\title{
Preparation and Properties of Probiotic Chocolates Using Yoghurt Powder
}

\author{
Ramakrishna Chetana, Sunki Reddy Yella Reddy ${ }^{*}$, Pradeep Singh Negi \\ Human Resource Development CSIR — Central Food Technological Research Institute (Council of Scientific and Industrial Research) \\ Mysore, India. \\ Email: ${ }^{*}$ syreddy52@gmail.com
}

Received January $2^{\text {nd }}, 2013$; revised February $7^{\text {th }}, 2013$; accepted February $15^{\text {th }}, 2013$

\begin{abstract}
Milk chocolates were prepared by replacing skim milk powder in the formulation with yoghurt powder at $50 \%$ and $100 \%$ levels. The effect of incorporating yoghurt powder on quality of chocolates was studied. No significant changes were observed in fatty acid profile and hardness of the chocolates. Sour taste of chocolate with yoghurt powder due to its acidity was neutralized by adding calculated amount of sodium bicarbonate. Sensory analysis showed that probiotic chocolates were highly acceptable and similar to control chocolate. Microbiological studies of chocolates showed the presence of Lactobacillus species to the extent of $3.37 \mathrm{log} \cdot \mathrm{cfu} / \mathrm{g}$, which were not present in the control sample prepared only with skim milk powder. Rheological studies showed that milk chocolate prepared using yoghurt powder at $50 \%$ showed no significant changes in yield value compared to that of control, but at $100 \%$ addition a considerable decrease in yield value was observed. Microstructural properties of chocolate with $50 \%$ addition of yoghurt powder showed smaller particles adhering to the cocoa and sugar crystals but at $100 \%$ addition of yoghurt powder, the cocoa particles were completely covered by smaller yoghurt powder matrix.
\end{abstract}

Keywords: Probiotic Chocolates; SEM; Rheology; Yoghurt Powder

\section{Introduction}

Chocolate is a suspension of fine solid particles of sugar, cocoa and milk powder in a continuous fat phase. Chocolates are solid at ambient $\left(20^{\circ} \mathrm{C}-25^{\circ} \mathrm{C}\right)$ and melt at body temperature $\left(37^{\circ} \mathrm{C}\right)$ giving a smooth suspension of particulate solids with a pleasing cooling sensation in the mouth [1]. The continuous phase influences the sensory characteristics such as mouth feel or melt in mouth.

Despite high fat and sugar contents, chocolate consumption makes a positive contribution to human nutriation through provision of antioxidants, principally polyphenols including flavonoids such as epicatechin, catechin and notably, the procyanidins [2]. Chocolates also contain minerals, specifically potassium, magnesium, copper and iron. Due to presence of cocoa, it is rich in natural antioxidants having health benefits. Milk solids added as spray-dried skimmed milk powder or full cream milk powder contributes to flavour, texture and liquid flow properties [3].

Numerous functional foods are consumed as part of a normal diet and they provide consumers with well-documented and physiological benefits such as probiotic bacteria. Probiotics are live microorganisms and proliferate

\footnotetext{
${ }^{*}$ Corresponding author.
}

in the human bowels that confer a health benefit by altering the enteric microflora. The main sources of these organisms are fermented dairy products, for example, yoghurts. However, the functional dairy product must contain a defined number of live probiotic bacteria (usually at least $10^{6} \mathrm{cfu} / \mathrm{g}$ ). Furthermore, their number at the end of the shelf life is the most important criterion when the health-promoting value of a given foodstuff is evaluated [4-7].

Probiotic bacteria beneficially affect human health by improving the gut micro biota balance and the defenses against pathogens. Additional health benefits attributed to probiotics are the stimulation of the immune system, blood cholesterol reduction, vitamin synthesis, anti-carcinogenesis and anti-bacterial activities. Two other important criteria to determine the efficacy and the success of the product containing probiotics are the acceptance of the product by the consumers and the survival of probiotic microorganisms during its production [8]. Lactobacilii, Bifido bacteria and several other lactic acid bacteria are regarded as probiotics, as they do not induce mucosal inflammation. The main sources of these organisms are fermented dairy products for example yoghurt (curd). In general, the food industry had applied the recommended level of $10^{6} \mathrm{cfu} / \mathrm{gm}$ at the time of consumption of lacto- 
bacillus acidiophilus, Bifidobacteria and other probiotic bacteria [9]. Traditional yoghurt is produced from milk, fermented by strains of Streptococcus thermophilus and Lactobacillus delbrueckii subsp. bulgaricus [10].

Today, India is the largest producer of milk in the world and the Indian dairy industry is witnessing rapid changes. Yoghurt/curd is the most popular fermented dairy product in India, prepared by the use of mixed mesophilic cultures that ferment lactose to lactic acid. Products like yoghurt are known more for their therapeutic significance than nutritional value [11]. It has a limited keeping quality of 1 - 2 days at ambient temperature and its quality is not retained for more than 1 week under refrigerated conditions [12]. Dried yoghurt powder has enhanced shelf life and it can also be used as a base for formulation of health foods. Nebesny et al. [13] have reported that chocolate formulated with isomalt and enriched with viable cells of lactic acid bacteria, introduced in the form of powdered yoghurt, is not only a sucrose-free, low-calorie product but additionally displays nutritional and dietetic attributes, and can be regarded as a functional food additional species in the fingerprints. Possemiers et al. [14] have reported bacteria and chocolate to be a successful combination for probiotic delivery. They have showed that coating of the probiotics in chocolate is an excellent solution to protect them from environmental stress conditions and for optimal delivery. The aims of the present study is to incorporate dried probiotic powder for the preparation of probiotic chocolate, and study the effects of replacing skim milk powder with yoghurt powder on the rheological and other quality parameters of milk chocolate.

\section{Materials and Methods}

\subsection{Composition of Yogurt}

Yoghurt was procured locally in bulk and used for the studies. The yoghurt had protein content was $3.3 \%$, fat $3.0 \%$, minerals $0.7 \%$, calcium $120 \mathrm{mg}$, vitamin A $35 \mathrm{ug}$ and carbohydrates (as Lactose) 3.9\%.

\subsection{Preparation of Yoghurt Powder}

The yoghurt was dried in a freeze drier (Lyophilisation Inc. USA, Model LT 5S): Freezing cycle : $-26^{\circ} \mathrm{C}$ for $2 \mathrm{~h}$, Drying cycle: $-25^{\circ} \mathrm{C}$ to $+25^{\circ} \mathrm{C}$ for $18 \mathrm{~h}$ and vacuum from $100,000 \mathrm{~m} \cdot$ torr to $250 \mathrm{~m} \cdot$ torr were used for a total period of $20 \mathrm{~h}$. The powder obtained was packed in polypro- pylene covers and stored in refrigerator.

\subsection{Composition of Yoghurt Powder}

The prepared yoghurt powder had of: $3.0 \%-3.5 \%$ moisture, $35 \%$ protein, $1.5 \%-2.0 \%$ fat, and total acidity of $5.8 \%$ as lactic acid.

\subsection{Preparation of Chocolate}

Milk chocolate was prepared using the formulation given in Table 1. Skim milk powder was replaced at $50 \%$ and $100 \%$ level by yoghurt powder in milk chocolate formulation and compared with control chocolate prepared with skim milk alone. All the ingredients were mixed and passed through a triple-roll chocolate refiner (Pascal, England), three times, keeping the distance between the rollers and number of passes constant for all the batches. The mass was then conched by adding the remaining cocoa butter and lecithin for $3 \mathrm{~h}$ at $50^{\circ} \mathrm{C}-55^{\circ} \mathrm{C}$. The mass after conching was taken for viscosity measurement. The mass was then tempered and moulded. The samples were kept at refrigerated condition for further analyses.

\subsection{Texture of Chocolate}

The hardness of the chocolate was measured using a Lloyd's texture measuring system (model LR 5K, UK). The samples of uniform dimension $(4 \times 8 \times 1 \mathrm{~cm} \cdot \mathrm{lbh})$, were conditioned by keeping at $25^{\circ} \mathrm{C} \pm 2^{\circ} \mathrm{C}$ for about $3 \mathrm{~h}$ before measuring. Penetration was measured at $25^{\circ} \mathrm{C} \pm$ $2^{\circ} \mathrm{C}$ using a probe of $3 \mathrm{~mm}$ dia at a speed of $50 \mathrm{~mm} / \mathrm{min}$ and $2 \mathrm{~mm}$ deflection using a $50 \mathrm{~N}$ load cell; the force required to penetrate was measured as hardness $(\mathrm{N})$ and an average of 12 measurements was reported.

\subsection{Fatty Acid Analysis}

The fat from chocolate samples was extracted with chloroform and converted to fatty acid methyl esters (FAME) using KOH/Methanol (AOCS, 1993). FAME were analysed by GC (Varian GC 450, Hercudiesweg, The Netherlands) with FID and using Supelco, SP-2340 $(0.25 \mathrm{~mm}$ $\times 30 \mathrm{~m}$ ) capillary column, programmed from $50^{\circ} \mathrm{C}$ to $200^{\circ} \mathrm{C}$ at $5^{\circ} \mathrm{C} / \mathrm{min}$ and maintaining at $200^{\circ} \mathrm{C}$ for $10 \mathrm{~min}$; injection temperature $230^{\circ} \mathrm{C}$, split ratio 1:20; detector temperature $240^{\circ} \mathrm{C}$ and nitrogen flow, $0.9 \mathrm{~mL} / \mathrm{min}$. The fatty acids were identified by using authentic standards and reported as relative percentage.

Table1. Viscosity of chocolates prepared with yoghurt powder.

\begin{tabular}{cccc}
\hline Chocolate & Casson Yield Value (Pa) $\boldsymbol{\tau}_{\mathbf{0}}$ & Casson Plastic Viscosity (Pa S) $\boldsymbol{\eta}_{\mathbf{p}}$ & $\mathbf{R}^{\mathbf{2}}$ \\
\hline Control & $40.23^{\mathrm{b}}$ & $1.87^{\mathrm{a}}$ & 0.99 \\
$50 \%$ Yoghurt Powder & $41.02^{\mathrm{b}}$ & $2.11^{\mathrm{a}}$ & 0.99 \\
$100 \%$ Yoghurt Powder & $28.65^{\mathrm{a}}$ & $3.76^{\mathrm{b}}$ & 0.99 \\
\hline
\end{tabular}

${ }^{a, b}$ Mean values $(n=6)$ bearing different superscripts in a column are significantly different $(\mathrm{p} \leq 0.05)$. 


\subsection{Viscosity Measurement}

The rheological behaviour of chocolate was measured at $40^{\circ} \mathrm{C}$ using HAAKE Viscotester, VT550 (Haake, Karlsruhe, Germany), using coaxial cylinder SV, from 0 to 100 shear rate in $3 \mathrm{~min}$, and the curves of shear rate versus shear stress and viscosity were recorded. The shear rate and shear stress curves were subjected to various rheological models to see the best fit and determine viscosity, using Rheo Win (Haake, Karlsruhe, Germany) software. All the measurements were made in triplicate and the average was reported. The basic casson equation is used to describe the flow behavior of chocolate. Casson yield value and plastic viscosity were used to describe the flow behavior of chocolate.

\subsection{Sensory Evaluation}

A trained panel was employed for carrying out sensory evaluation of chocolate by following the method of Quantitative Descriptive Analysis (QDA). The definitions of the attributes were discussed and descriptors were developed by asking the panelists to describe the product with the suitable descriptive terms for development of a score card, which consisted of each attribute on a $15-\mathrm{cm}$ line scale. Quantitative descriptive analysis methods were adopted and the panelists were asked to mark the intensity of each attribute [15]. The main desirable sensory attributes of chocolate, such as gloss, snap, melt-in-mouth, sweetness, chocolate flavour and overall quality were assessed by a panel of 15 trained judges. Calculated amount of sodium bicarbonate based on their neutralization equivalent of the total acid present in yoghurt powder was added to the chocolates to avoid the acidic taste in chocolates. The judges were asked to mark by drawing a vertical line on the scale for all quality attributes of the coded samples.

\subsection{Scanning Electron Microscope (SEM)}

The microstructure of chocolate samples was studied by SEM using LEO Scanning electron model 435 VP (Leo electronics system, Cambridge, UK). The chocolate was defatted with hexane and placed on the sample holder with the help of a double scotch tape and sputter coated with gold (2 min, $2 \mathrm{~m}$ Bar) where it was observed at 15 $\mathrm{kV}$.

\subsection{Statistical Analysis}

Data obtained was statistically analysed using Duncan's Multiple Range Test (DMRT) at significant level of $\mathrm{P} \leq$ 0.05 [16]. All the analyses were performed in triplicate except for texture $(n=12)$. The mean values with standard deviations (SD) are reported.

\subsection{Microbiological Analysis}

Number of Lactobacilli was counted by pour plate method using $1 \mathrm{ml}$ of appropriate dilution of each sample in De Man Rogosa-Sharpe agar (MRS agar, Hi media, Mumbai). After 2 days of incubation at $37^{\circ} \mathrm{C}$ the colonies were counted and the results expressed in logarithm of colonies forming units per gram of product $(\log \cdot \mathrm{cfu} / \mathrm{g})$. The representative colonies were tested for absence of catalase to confirm the presence of $\mathrm{LAB}$

\section{Results and Discussion}

\subsection{Viscosity of Chocolates}

The viscosity of chocolate plays an important role during manufacture of chocolate. The solid ingredients, processing parameters and amount of fat influence viscosity of chocolate mass. The rheological behavior of chocolate followed non-Newtonian flow, as reported in literature, due to presence of solids in molten fat and followed the Casson model, which is the best fit as shown by the correlation coefficient (Table 1). Casson model is recommended by IOCCC [17] and has been used as an internationally accepted standard model for determination of viscosity of chocolates. It is now accepted and applied as an appropriate mathematical model for predicting flow behavior and rheological analysis of different kinds of chocolates [18,19].

Milk chocolate prepared using yoghurt powder at 50\% by weight of milk powder showed no significant changes in yield value compared to that of control chocolate prepared with milk powder. However, chocolate with $100 \%$ addition of yoghurt powder showed considerable decrease in yield value. Plastic viscosity of chocolate increased with increase in addition of yoghurt powder from $50 \%$ to $100 \%$ (Table 1), which may be due to finer particles of yoghurt powder compared to milk solids.

\subsection{Texture of Chocolate}

Only marginal differences in hardness were observed among the chocolates, i.e., control and with added yoghurt powder, ranging from 34 to $36 \mathrm{~N}$.

\subsection{Fatty Acid Composition}

No significant differences in fatty acid composition were observed among the chocolates prepared with yoghurt powder as all samples contain cocoa butter and milk fat as fat sources (Table 2). Short chain fatty acids are from milk fat from milk powder or yoghurt powder. The product contains about $30 \%$ of monounsaturated (oleic) fatty acids and equal quantity of stearic acid, which is neutral with respect to affecting serum cholesterol [20]. 
Table 2. Fatty acid composition (\%) of fat in chocolates prepared with yoghurt powder.

\begin{tabular}{cccc}
\hline \multirow{2}{*}{ Fatty Acid } & \multicolumn{3}{c}{ Chocolate with } \\
\cline { 2 - 4 } & Control & $\mathbf{5 0 \%}$ Yoghurt Powder & $\mathbf{1 0 0 \%}$ Yoghurt Powder \\
\hline C4:0 & 2.50 & 2.45 & 2.50 \\
C10:0 & 1.50 & - & - \\
C14:0 & 0.42 & 0.71 & 1.32 \\
C16:0 & 24.63 & 25.18 & 25.87 \\
C18:0 & 34.61 & 35.07 & 34.56 \\
C18:1 & 32.2 & 32.32 & 32.82 \\
C18:2 & 4.00 & 3.00 & 2.96 \\
\hline
\end{tabular}

Mean values $(n=3)$.

\subsection{Microstructural Properties of Probiotic Chocolates}

The outer topography of probiotic milk chocolates were assessed by SEM (Figures 1(a)-(c)), in order to study the effect of addition of yoghurt powder into chocolates. Figure 1(a) shows coarse particles of cocoa mass sheared during refining and conching process in the manufacture of chocolate. A few sugar particles and skim milk powder can also be seen along with the cocoa mass. Skim milk powder particles are smaller than cocoa and sugar particles and adhere to the larger and coarser cocoa particles.

In chocolates with $50 \%$ addition of yoghurt powder, the smaller particles adhering to the cocoa and sugar crystals are more in number (Figure 1(b)). In chocolate with $100 \%$ addition of yoghurt powder, the cocoa particles are completely covered by smaller yoghurt powder matrix (Figure 1(c)). Skim milk powder shows surface dents, which can be attributed to the atomization conditions [21] but yoghurt powder which is freeze dried has smaller particle size compared to skim milk powder which forms a cluster around the larger cocoa and sugar particles without dents.

\subsection{Microbiological Studies}

Microbiological studies revealed that the chocolates prepared with yoghurt powder showed the presence of lactic acid bacteria to the extent of $3.37 \log \cdot \mathrm{cfu} / \mathrm{g}$, which were not present in the control sample prepared only with skim milk powder (Table 3). There was no significant increase in the viable $\mathrm{LAB}$ count in $100 \%$ substitution over $50 \%$ as the cells were exposed (as seen in SEM) and probably they were more susceptible to processing treatments. It is well established that foods containing viable lactic acid bacteria as probiotics, improve gut health.

\subsection{Sensory Analysis}

Sensory evaluation revealed that chocolate with $50 \%$ addition of yoghurt powder was more acceptable than

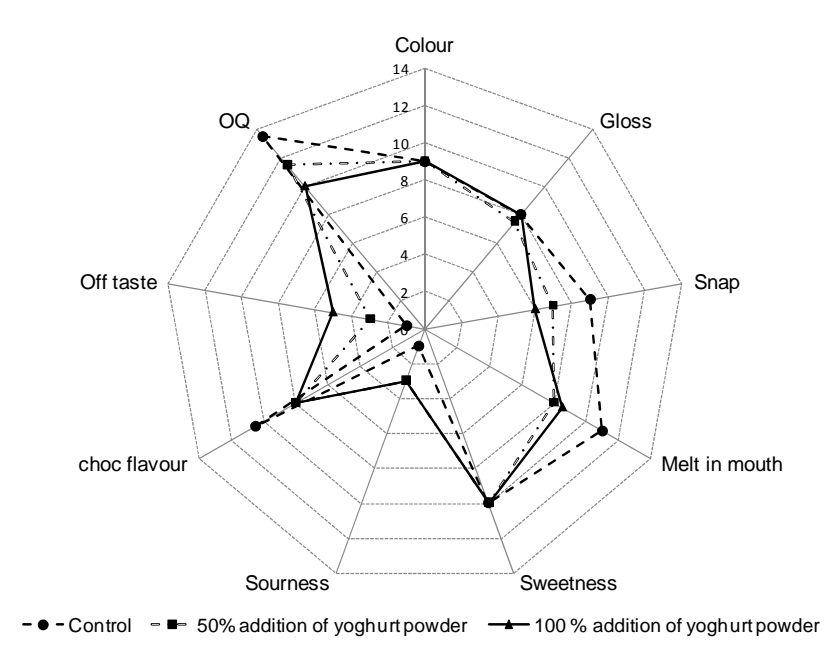

Figure 1. Sensory evaluation of chocolates prepared with yoghurt powder.

Table 3. Microbiological studies of chocolates prepared with yoghurt powder.

\begin{tabular}{cc}
\hline Samples & Lactobacillus $\boldsymbol{s} \boldsymbol{p}$. $(\mathbf{l o g} \cdot \mathbf{c f u} / \mathbf{g})$ \\
\hline Yoghurt Powder & $4.758 \pm 0.11^{\mathrm{b}}$ \\
$50 \%$ Yoghurt Powder & $3.581 \pm 0.23^{\mathrm{a}}$ \\
$100 \%$ Yoghurt Powder & $3.586 \pm 0.24^{\mathrm{a}}$ \\
Control & $-\mathrm{Nil}-$ \\
\hline
\end{tabular}

Mean values $(n=6)$ bearing different superscripts in a column are significantly different $(\mathrm{p} \leq 0.05)$.

that with $100 \%$ addition and both had slightly lower overall quality when compared to control prepared only with skim milk powder (Figure 2). No significant differences were observed in attributes such as colour, gloss and sweetness among all the three samples. Snap, melt in mouth and chocolate flavour attributes decreased with addition of yoghurt powder. Chocolates with added yoghurt powder are sour in taste due to acid present in yoghurt powder. However, chocolates with addition of required amount of sodium bicarbonate to neutralize the acid did not show any sour taste. Similar results have been reported by Nebesny et al. [13], where sensory 


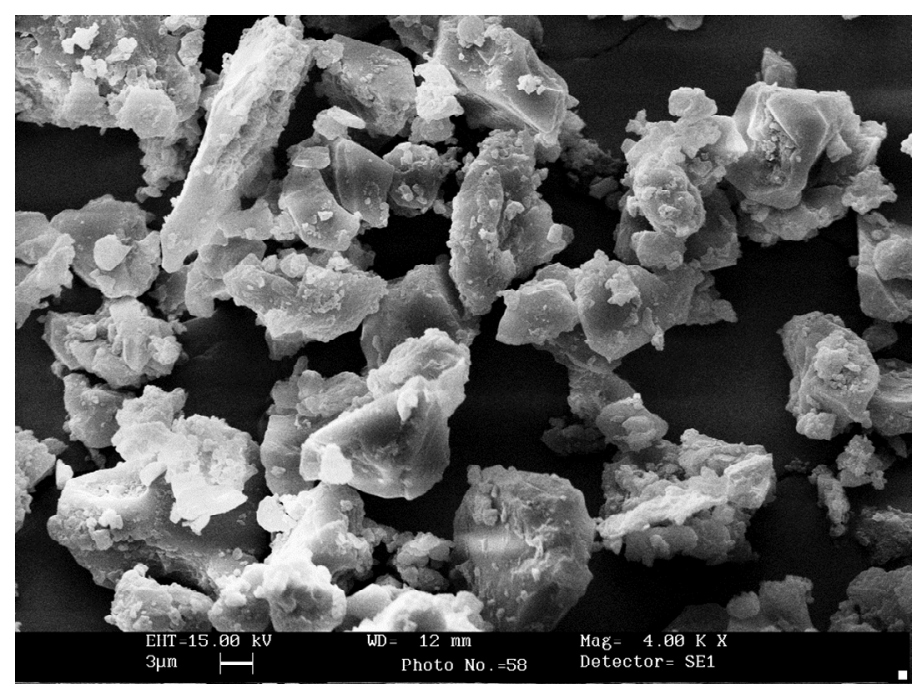

(a) Control chocolate

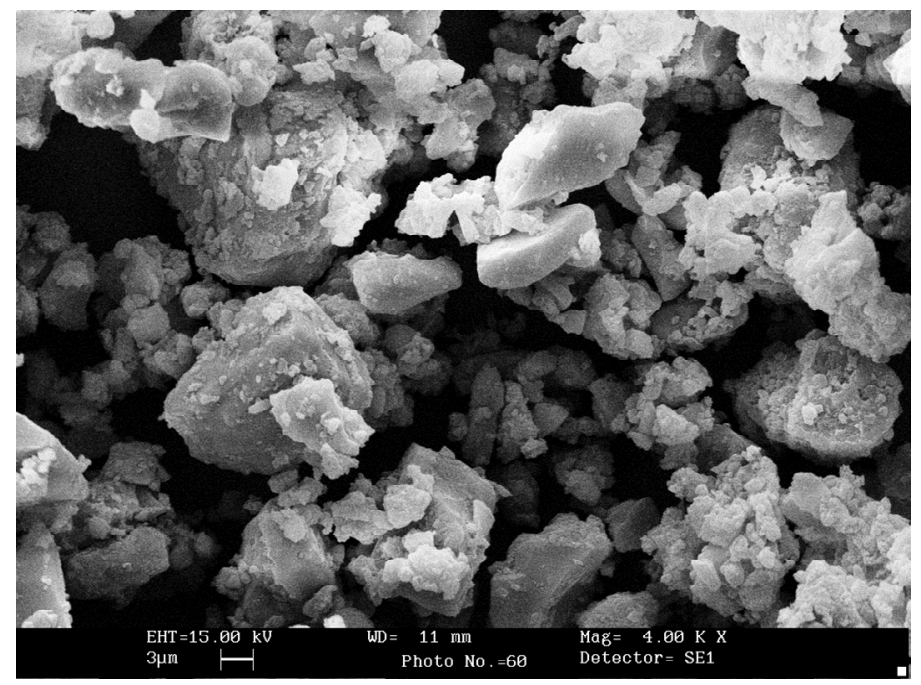

(b) Chocolate with $50 \%$ addition of yoghurt powder

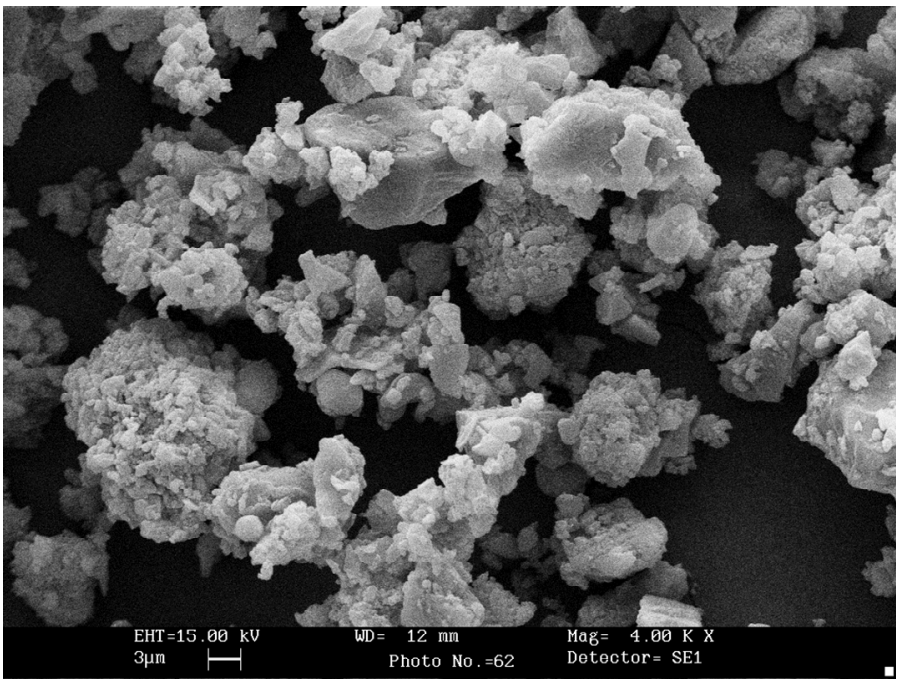

(c) Chocolate with 100 addition of yoghurt powder

Figure 2. Scanning electron micrographs (SEM) of chocolates prepared with yoghurt powder (Mag. 4000×). 
attributes of sucrose-free yoghurt-containing dark and milk chocolates and their yoghurt-free counterparts revealed excellent quality. The sensory attributes of yoghurt and isomalt containing dark chocolates received a high average score which was only slightly lower than that of analogous milk chocolates.

\section{Conclusion}

Milk chocolate with yoghurt powder was prepared replacing milk powder to make it probiotic. Marginal differences in viscosity, texture and sensory evaluation of chocolate with yoghurt were observed in comparison with those of control milk chocolate. Chocolate with yoghurt powder contain probiotic lactobacilli species and thus making it probiotic. Chocolate is reported to contain natural antioxidants and the nutritional quality of this was further enhanced by making it probiotic. Thus, milk chocolate with probiotic yoghurt powder was prepared without affecting the desirable quality of conventional chocolate.

\section{REFERENCES}

[1] S. T. Beckett, "Conching," In: S. T. Beckett, Ed., Industrial Chocolate Manufacture and Use, 3rd Edition, Blackwell Science, Oxford, 1999, pp. 1-81.

[2] C. L. Hii, C. L. Law, S. Suzannah, S. Miswani and M. Cloke, "Polyphenols in Cocoa (Theobroma cacao L.)," Asian Journal of Food and Agro Industries, Vol. 2, No. 4, 2009, pp. 702-722.

[3] S. J. Haylock and T. M. Dodds, "Ingredients from Milk," In: S. T. Beckett, Ed., Industrial Chocolate Manufacture and Use, 3rd Edition, Blackwell Science, Oxford, 1999, pp. 1-77.

[4] B. German, E. J. Schiffrin, R. Reniero, B. Mollet, A. Pfeifer and J. R. Neeser. "The Development of Functional Foods: Lessons from the Gut," Trends in Biotechnology, Vol. 17, No. 12, 1999, pp. 492-499.

[5] M. A. F. Belem, "Application of Biotechnology in the Product Development of Nutraceuticals in Canada," Trends Food Science and Technology, Vol. 10, No. 3, 1999, pp. 101-106. doi:10.1016/S0924-2244(99)00029-1

[6] N. M. Childs, "Nutraceutical Industry Trends," Journal of Nutraceutical, Functional and Medicinal Foods, Vol. 2, No. 1, 1999, pp. 73-85. doi:10.1300/J133v02n01 07

[7] C. J. Dillard and J. B. German, "Phytochemicals: Nutraceuticals and Human Health," Journal of Food Agricultural Sciences, Vol. 80, No. 12, 2000, pp. 1744-1756. doi:10.1002/1097-0010(20000915)80:12<1744::AID-JSF A725>3.0.CO;2-W

[8] C. N. Heenan, M. C. Adams, R. W. Hosken and G. H. Fleet, "Survival and Sensory Acceptability of Probiotic Microorganisms in a Non-Fermented Frozen Vegetarian Dessert," LWT_Food Science \& Technology, Vol. 37 No.

\section{4, 2004, pp. 461-466. doi:10.1016/j.1wt.2003.11.001}

[9] T. D. Boylston, C. G. Vinderola, H. B. Ghoddusi and J. A. Reinheimer, "Incorporation of Bifidobacteria into Cheeses: Challenges and Rewards," International Dairy Journal, Vol. 14, No. 5, 2004, pp. 375-387. doi:10.1016/j.idairyj.2003.08.008

[10] V. Xanthopoulos, D. Petridis and N. Tzanetakis, "Characterization and Classification of Streptococcus thermophilus and Lactobaccilus delbrueckii Sub Species Bulgaricus Strains Isolated from Traditional Greek Yoghurt," Journal of Food Science, Vol. 66, No. 5, 2001, pp. 747752. doi:10.1111/j.1365-2621.2001.tb04632.x

[11] R. P. Aneja, B. N. Mathur, R. C. Chandan and A. K. Banerjee, "Technology of Indian Milk Products," Dairy India Year Book Publications, New Delhi, 2002.

[12] M. Kamruzzaman, M. N. Islam and M. M. Rahman, "Shelf life of Different Types of Dahi at Room and Refrigeration Temperature," Pakistan Journal of Nutrition, Vol. 1, No. 6, 2002, pp. 263-266.

[13] E. Nebesny, D. Żyżelewicz, I. Motyl and Z. Libudzisz, "Properties of Sucrose-Free Chocolates Enriched with Viable Lactic Acid Bacteria," European Food Research and Technology, Vol. 220, No. 3-4, 2004, pp. 358-362. doi:10.1007/s00217-004-1069-0

[14] S. Possemiers, M. Marzorati, W. Verstraete and T. Van de Wiele, "Bacteria and Chocolate: A Successful Combination for Probiotic Delivery," International Journal of Food Microbiology, Vol. 141, No. 1-2, 2010, pp. 97-103. doi:10.1016/j.ijfoodmicro.2010.03.008

[15] H. Stone and J. L. Sidel, "Sensory Evaluation Practices," 3rd Edition, Academic Press/Elsevier, London/New York, 2004.

[16] B. D. Duncan, "Multiple Range and Multiple F-Test," Biometrics, Vol. 11, No. 1, 1955, pp. 1-42. doi: $10.2307 / 3001478$

[17] IOCCC (International Office of Cocoa, Chocolate, and Sugar Confectionery), "Viscosity of Cocoa and Chocolate Products (Analytical Method: 46)," CABISCO, Brussels, 2000.

[18] S. Abbasi, "Food Texture and Viscosity: Concept and Measurement," Marzedanesh Publishers, Tehran, 2007. (in Farsi)

[19] J. Chevalley, "Chocolate Flow Properties," In: S. T. Beckett, Ed., Industrial Chocolate Manufacture and Use, 3rd Edition, Blackwell Science, Oxford, 1999, pp. 182200.

[20] W. E. Connor, "Harbingers of Coronary Heart Disease: Dietary Saturated Fatty Acids and Cholesterol. Is Chocolate Benign Because of Its Stearic Acid Content?" American Journal of Clinical Nutrition, Vol. 70, No. 6, 1999, pp. 951-952.

[21] E. Bylaite, P. R. Venskutonis and R. Mapdbieriene, "Properties of Caraway (Carum carvi L.) Essential Oil Encapsulated into Milk Protein-Based Matrices," European Food Research Technology, 2001, Vol. 212, No. 6, pp. 661-670. doi:10.1007/s002170100297 